\title{
Design of 3D Data Model of Underground Utilities in Korea Using CityGML Application Domain Extension
}

\author{
Da Woon Jeong, ${ }^{1}$ Seon Cheol Yu, ${ }^{2}$ and Jong Wook Ahn ${ }^{2 *}$ \\ ${ }^{1}$ Smart Urban Space Institute, Anyang University, \\ 22, Smadeok-ro 37beon-gil, Manan-gu, Anayang-si, Gyeonggi-do 14028, Korea \\ ${ }^{2}$ Dept. of Smart City Engineering, Anyang University, \\ 22, Smadeok-ro 37beon-gil, Manan-gu, Anayang-si, Gyeonggi-do 14028, Korea
}

(Received July 15, 2021; accepted September 27, 2021; online published December 21, 2021)

keywords: 3D data model, underground utilities, CityGML, utility network, Korea

In this study, we establish a 3D data model of underground utilities that applies international spatial information standards correspondingly, and we design a data model on the basis of this model to improve the systematic construction and management of underground utilities information and its accuracy and quality. The detailed research procedure is as follows. First, through a review of the existing system status and preceding studies, the necessity of this study and how it is differentiated from existing studies are derived by reviewing domestic and overseas research trends related to underground utilities and the current status of existing underground information systems. Second, considering the establishment of a 3D data model, we selected a reference model suitable for expressing underground utilities information by comparing and reviewing international standards, and this model was used as the basis of the data model. Lastly, regarding the design of a data model for underground utilities, a 3D data model of an underground utility based on international standards was designed using a Unified Modeling Language (UML) diagram based on previously defined contents. On the basis of these results, it is expected that the 3D data model for underground utilities with improved consistency with the real world for both above-ground and underground spaces will improve the accuracy and utilization of existing underground information.

\section{Introduction}

The use of underground space began with the history of mankind. The active development and use of underground space have gradually and actively progressed with the passage of time and the development of cities. However, if a disaster that can paralyze facilities in an instant, such as a fire, occurs in an underground space, or an accident occurs due to aging and lack of proper maintenance, a city's function will be paralyzed, citizens may panic, and the economic and social damage may be very large due to difficulties in restoring facilities. The absence of a systematic underground space development policy in a rapidly developed city may cause accidents in facilities built unmethodically underground. ${ }^{(1)}$

${ }^{*}$ Corresponding author: e-mail: ajw0603@anyang.ac.kr

https://doi.org/10.18494/SAM.2021.3542 
Under these circumstances, the Korean government enacted and enforced the Special Act on Underground Safety Management in January 2018 along with the development of an Integrated Map for Underground Spaces with the goal of strengthening underground safety management. The Integrated Map for Underground Spaces Development Project of Korea was established to integrate 15 types of underground information that constitute underground spaces, such as underground utilities and structures (12 types) and ground information (three types), into 3D maps for cities across the country by 2020. The Integrated Map for Underground Spaces constructed so far is serviced through the Underground Information Utilization Support Center operated by the Korea Institute of Civil Engineering and Building Technology, but its utility is low due to problems such as an inefficient update system, low accuracy, and information security. Also, regarding the Integrated Map for Underground Spaces, the Board of Audit and Inspection (BAI) pointed out that underground utilities lack quality management on information because errors in the conversion and transfer of attribute information to three dimensions cannot be corrected because another organization has the data management authority. ${ }^{(2)}$

As described above, it is necessary to develop a standardized data model in terms of spatial information to solve various problems caused by the limited accuracy of underground utilities information. In particular, it is necessary to expand the 3D spatial information developed with focus on the existing above-ground space to the underground space to improve the development, management, and utilization of services of related information for complex and unclear underground spaces. To this end, in this study, we established a data model design method for underground utilities such as waterworks, sewerage, and electric power specified in the Regulations on the Production of the Integrated Map for Underground Spaces of Korea, and designed a data model that complies with international standards.

\section{Review of Existing System Status and Preceding Studies}

\subsection{Review of existing system status}

To review the existing system status, the Integrated Underground Facilities System and the Integrated Map for Underground Spaces, promoted as a national project in Korea, were examined in detail.

The Underground Facilities Integration System Development Project of Korea was established to build and integrate information on the seven major underground utilities (waterworks, sewage, gas, electric power, heating, communication, and oil supply) that are buried underground below roads. Underground utilities have different accuracy verification standards for each management entity (agency). To resolve this issue, an integrated underground facilities system and database were developed, and operations to ensure accuracy, such as a data quality review, have been carried out. This system collects data presented in various formats in each institution, converts the data into an integrated format, and provides integrated data that can be used by local governments. The integrated underground facilities database contains the data of pipelines, etc., and consists of a total of 22 types of basic maps, 128 types of facility maps, and 160 types of data codes. The system provides data in the integrated underground 
facilities database to the local governments of approximately 135 cities and provinces to support facilities management, guaranteeing high accuracy. In this regard, the data are provided to various organizations such as the Underground Information Utilization Support Center of Korea Institute of Civil Engineering and Building Technology, the National Disaster Management Institute, and the Geum River Flood Control Office, which are public institutions of Korea. The data are also used to produce the Integrated Map for Underground Spaces and the inland flood risk map and assess underground safety impact.

The Integrated Map for Underground Spaces Development Project was established to build and utilize a 3D-based integrated map for underground spaces as a part of Korea's ground subsidence prevention measures. The Integrated Map for Underground Spaces is composed of information on underground facilities (six types), underground structures (six types), and the ground (three types), which constitute key components (Table 1). It not only shows comprehensive information about the underground space at a glance, but is also used as the base data to cope with and analyze accidents such as ground subsidence. Also, map information is provided to local governments so that private and public institutions can use the information when carrying out underground construction. The progress of the Integrated Map for Underground Spaces is as follows. As of 2019, the map has been completed for the eight major metropolitan cities and 17 cities in Gyeonggi-do, and services have been provided to local government officials through the Underground Information Utilization System. In addition, the map will be completed for the remaining 60 cities by 2021 and for all 77 counties by 2023. ${ }^{(3)}$

\subsection{Preceding studies}

Becker et al. ${ }^{(4)}$ proposed requirements for integrated 3D modeling for major infrastructure in cities and a new framework. The utility network components were modeled according to the complementary graph structure embedded in the 3D topography and the $3 \mathrm{D}$ space. The foundation for multi-facility simulation and interdependent critical infrastructure analysis was prepared through the proposed framework, and a method of mapping the existing data set modeled according to this approach to the framework was proposed. Specifically, various types of facility network objects such as water and gas pipes, cables, valves, pumps, and switchgear cabinets were expanded as the core model of the CityGML Utility Network Application Domain Extension (ADE) model.

Table 1

Major contents of integrated map for underground spaces by subject.

\begin{tabular}{ll}
\hline Division & Major contents by subject \\
\hline $\begin{array}{l}\text { Underground } \\
\text { facilities }\end{array}$ & $\begin{array}{l}\text { - Six types of underground facilities artificially buried in the underground space } \\
\text { - Waterworks, sewerage, communication, heating, electric power, gas }\end{array}$ \\
\hline $\begin{array}{l}\text { Underground } \\
\text { structure }\end{array}$ & $\begin{array}{l}\text { - Six types of underground structures artificially produced in the underground space } \\
\text { - Subway, pipe utility conduit, underground shopping mall, underpass, pedestrian underpass, } \\
\text { underground parking lot }\end{array}$ \\
\hline Ground & $\begin{array}{l}\text { - Information about drilling, geology, and tubular wells of soil and rock formations naturally } \\
\text { formed in the subterranean space }\end{array}$ \\
\hline
\end{tabular}


Hijazi et al..$^{(5)}$ aimed to evaluate the functions of various network models, including the CityGML Utility Network ADE model, to meet the requirements of the underground utilities network infrastructure. The requirements were extracted from a list of use cases defined by experts in several domains, and most CityGML Utility Network ADE models were found to be integrative schemas that can understand relationships with city objects through connections between different network systems. In addition, their study introduced examples of the limitations and functions of various network data models.

Becker et al. ${ }^{(6)}$ described how to define the concept and class of underground utilities to meet the requirements of complex analysis and simulation and how to define the attributes of a specific network in relation to 3D topography, network connectivity, and functional aspects. The model proposed in their study improved the possibility of exchanging or connecting data between different systems through a superset in relation to model representation.

Kutzner and Kolbe ${ }^{(7)}$ argued that the CityGML Utility Network ADE model is suitable for modeling heterogeneous networks in the context of a 3D city model. They introduced a CityGML Utility Network ADE model that adds various functional aspects in relation to the modeling of the supply area, the specialization of city objects and network functions following functional roles, the potential supply of a medium for city objects, the representation of current supply, and so forth. Their newly defined CityGML Utility Network ADE model was developed using Enterprise Architect software. Also, the corresponding XML schema file was successfully derived from the UML model through ShapeChange software, and the network information was converted from shp and dxf files to CityGML.

Kutzner and Kolbe ${ }^{(8)}$ also developed a 3D network model for the simulation of multi-facility failures, including attributes by subject (type of use, medium, material, operational parameters, and number of affected citizens). Also, the effectiveness and utility of the study were demonstrated through many use cases such as the simulation analysis of waterworks pipelines, sewage pipelines, and electrical pipelines.

Boates et al. ${ }^{(9)}$ introduced a method of mapping the CityGML Utility Network ADE model to a relational database schema. For this, a sample of a fresh water network that used the CityGML Utility Network ADE model based on data from the Canadian city of Nanaimo was also provided. This sample is a relational database schema built on the basis of 3DCityDB by extending the schema of the CityGML Utility Network ADE model.

Duijn et al. ${ }^{(10)}$ presented a 3D data modeling approach for the integrated management of underground utilities networks and related above-ground city objects. This approach first manipulated the structure of the existing facility data in commonly used FME ETL software to ensure that the data conform to the CityGML Utility Network ADE model. Then, CityGML data were stored in 3DCityDB to manage the facility network data. In this study, it was verified that 3DCityDB is suitable for performing graph-based topological tasks through PostgreSQL and pgRouting extensions.

Kutzner et al. ${ }^{(11)}$ proposed an extended concept of $\mathrm{ADE}$ development through extensive analysis on the use cases of the CityGML Utility Network ADE model. For this purpose, a list of requirements was first prepared, and the current data model was compared and evaluated on the basis of these requirements. In addition, the concept of a node-link network connecting network 
components to city objects, functional properties in objects, a refined network of component objects, and a new electrical network package were presented.

In the study of Ortega et al., ${ }^{(12)}$ various geometric modeling approaches were presented to propose an appropriate data visualization method. A multimodal prototype was developed using various algorithms to include invisible underground objects as a part of the city model. This prototype was developed as a part of MultiVis, a geospatial information system (GIS) for portable IOS and Android devices.

\subsection{Implications}

According to the review of the existing system status, the Integrated Underground Facilities System plays the role of an integrated system related to the construction, management, and inquiry of 2D underground facilities information, but there are continuously arising issues in terms of reliability and accuracy of data such as geometric and topological nonconformity between objects and low position accuracy. Even the Integrated Map for Underground Spaces repeats problems arising from the existing $2 \mathrm{D}$ underground facilities information because the information about underground facilities is collected from the Integrated Underground Facilities System and visualized in a 3D form.

According to the review of previous studies, most studies designed data models using spatial information standards, such as the ISO 19100 series, mainly for the above-ground area, or expanded data models for various fields by applying international standards such as CityGML. However, there have been a limited number of studies related to the design and application of data models in the underground area. Even so, a few previous studies presented a data model construction method and various scenarios for modeling complex interdependencies centered on pipelines and valves, the major objects of underground utilities, and for conducting analyses such as network simulation. There are also cases that approached various modeling development methods, including agent-based modeling, effects-based operational modeling, mathematical models, and risk-based models. The limitations that are commonly revealed in studies are as follows. First, underground space is expressed with a significantly lower level of detail (LoD) such as $2 \mathrm{D}$ than the above-ground area, and it does not have an LoD system as diverse as the above-ground area. Second, existing studies on data models for underground utilities mainly target only objects such as pipelines, valves, and manholes, and thus, a more detailed and expanded model is required to express various underground utility objects in the real world. Finally, there is lack of plans that are associated with buildings and topography, which are city objects, in addition to the underground space. ${ }^{(13,14)}$

By referring to the underground information previously constructed in Korea, various underground utility objects in addition to pipelines, manholes, and valve objects are designed according to international standards. On the basis of these settings, we consider our study to have academic and technical value because it establishes a detailed design plan for a 3D data model of underground utilities and designs the data model. The differences between major studies and this study are summarized in Table 2 . 
Table 2

Preceding studies and distinctive features of this study.

\begin{tabular}{|c|c|c|c|}
\hline Study by & & Major content & Limitations \\
\hline \multirow[b]{2}{*}{$\begin{array}{l}\text { Existing } \\
\text { system }\end{array}$} & $\begin{array}{l}\text { Integrated } \\
\text { system of } \\
\text { underground } \\
\text { facilities }\end{array}$ & $\begin{array}{l}\text { Project for integrating information on } \\
\text { facilities buried under roads. } \\
\text { Verifies data-related accuracy available } \\
\text { to local governments, and generates and } \\
\text { provides underground safety-related } \\
\text { statistics }\end{array}$ & $\begin{array}{l}\text { Geometric forms such as points, lines, } \\
\text { and planes exist in the constructed layer, } \\
\text { but the topological relationship between } \\
\text { objects is not defined } \\
\text { Accuracy issues such as depth and } \\
\text { coordinate inconsistency related to } \\
\text { attribute information }\end{array}$ \\
\hline & $\begin{array}{l}\text { Integrated } \\
\text { map for } \\
\text { underground } \\
\text { spaces }\end{array}$ & $\begin{array}{l}\text { 3D map information that shows } \\
\text { comprehensive information about the } \\
\text { underground space at a glance } \\
\text { For underground facilities, it } \\
\text { collects } 2 \mathrm{D} \text { information built in the } \\
\text { underground facilities integration } \\
\text { system and converts it into 3D } \\
\text { information } \\
\text { May be used as basic data to cope with } \\
\text { and analyze accidents such as ground } \\
\text { subsidence }\end{array}$ & $\begin{array}{l}\text { Because it collects layer and attribute } \\
\text { information of the integrated underground } \\
\text { facilities system, the problems that occur } \\
\text { in the integrated underground facilities } \\
\text { system reoccur } \\
\text { Problems in terms of information } \\
\text { accuracy such as information omission } \\
\text { and absence are exposed when } \\
\text { constructing additional 3D information }\end{array}$ \\
\hline \multirow[t]{2}{*}{$\begin{array}{l}\text { Preceding } \\
\text { studies }\end{array}$} & Duijn et al. & $\begin{array}{l}\text { Studied 3D data modeling for integrated } \\
\text { management of above-ground city } \\
\text { objects related to underground utilities }\end{array}$ & $\begin{array}{l}\text { Expressed only network forms such as } \\
\text { nodes and links of pipeline objects in } \\
\text { underground utilities } \\
\text { The topology for the network between } \\
\text { pipeline objects was designed, but it was } \\
\text { only expressed as 2D information }\end{array}$ \\
\hline & Kutzner et al. & $\begin{array}{l}\text { Proposed an extended ADE model } \\
\text { through analysis of the use cases of the } \\
\text { CityGML Utility Network ADE model }\end{array}$ & $\begin{array}{l}\text { Network component module lacks the } \\
\text { attributes related to underground utilities, } \\
\text { and objects and LoD are expressed in two } \\
\text { dimensions }\end{array}$ \\
\hline Our study & & \multicolumn{2}{|c|}{$\begin{array}{l}\text { For data integration and interoperability with above-ground area in the future, we } \\
\text { select international standards that support them and design a 3D data model of } \\
\text { underground utilities on this basis }\end{array}$} \\
\hline
\end{tabular}

\section{Establishment of 3D Data Model}

\subsection{Selection of reference model}

In this section, we compare and analyze international standards related to 3D data models to design a 3D data model of underground utilities. The 3D data model should include various domain information and be compatible with other data and application systems. In other words, selecting a data model that satisfies these conditions is a very important process. For this purpose, various international standards related to 3D data models of underground utilities discussed in previous studies were selected as a comparison group in this study. The models were INSPIRE Utility Network, IFC, ArcGIS Utility Network, SEDRIS, ${ }^{(15)}$ PipelineML, ${ }^{(16)}$ MUDDI, ${ }^{(17)}$ and the CityGML Utility Network ADE model, ${ }^{(18)}$ and international standards were compared and analyzed on the basis of the specifications in standards documents and related research reports. 
The criteria used for comparison and analysis to international standards are spatial scope, spatial representation, semantics, spatial-logical relationships, visualization, and sensors/time series data. Four levels were used in the evaluation: not supported, basically supported, supported in detail, and comprehensively supported.

INSPIRE is a multinational and multi-institutional geospatial information infrastructure and a framework for sharing data within the European Union (EU). INSPIRE can classify network objects (pipes, cables) but does not provide functions for adding network elements and extending domains. It cannot display links between different types of networks. IFC provides $2 \mathrm{D}$ and $3 \mathrm{D}$ representations of network objects. The IFC data model can only express facilities at the building level and does not support small/large-scale urban network integration and expression. ArcGIS provides two sets of network data models for managing logical and physical relationships in a network. However, this model is unable to express the network form as a 3D object or define and manage logical relationships between network objects. SEDRIS, the ISO standard, focuses on the expression and exchange of synthetic environments and supports modeling networks for oil, gas, chemicals, electricity, fresh water, and wastewater. SEDRIS was developed for the US Department of Defense's training simulation and has so far only been applied in the military field. Data format ambiguity and limited software support are its disadvantages. PipelineML is a geography markup language (GML)-based standard currently being developed by OGC for pipeline data exchange focused on the oil and gas industry. At the current level, various categories related to underground utilities and various above-ground or underground objects such as pumping stations are not considered. Also, the topology of the network can be set only for the nodes and links of the pipeline. MUDDI is a conceptual model proposed by OGC and represents the sub-surface network infrastructure including the surface environment. Key perspectives focus on data integration, visualization (2D-4D, AR), data quality and consistency, dependency analysis, digital twins, and simulations. However, it is currently at the research level and much work is needed for it to reach the commercialization stage. Finally, the CityGML Utility Network ADE model can model different types of networks such as electricity, fresh water, wastewater, gas, and telecommunication networks. In particular, this model represents and supports topological networks such as supply and disposal in 3D city model applications. The results of comparing international standards related to the 3D data model are shown in Table 3 by referring to the study of Kutzner et al. ${ }^{(11)}$

In summary, it is deemed that the CityGML Utility Network ADE model is the most suitable reference model for the development of a 3D data model of pipe-type underground utilities because it comprehensively supports most of the comparative criteria and can be flexibly extended. Also, CityGML comprehensively deals with various objects constituting a city, such as buildings, bridges, tunnels, and roads, and efficiently models 3D objects in macroscopic and microscopic scales. To develop it into an integrated model that considers the connection with above-ground space as well as underground space in the future, as described in the introduction, a data model that can express and support both above-ground and underground spaces, such as CityGML, is required. CityGML can also guarantee high reliability as an official standard of OGC that deals with international standards for spatial information and has already been used as 
Table 3

Comparison between international standard data models.

\begin{tabular}{|c|c|c|c|c|c|c|c|c|}
\hline Division & & $\begin{array}{l}\text { INSPIRE } \\
\text { Utility } \\
\text { Network }\end{array}$ & IFC & $\begin{array}{l}\text { ArcGIS } \\
\text { Utility } \\
\text { Network }\end{array}$ & SEDRIS & PipelineML & MUDDI & $\begin{array}{l}\text { CityGML } \\
\text { Utility } \\
\text { Network } \\
\text { ADE } \\
\end{array}$ \\
\hline \multirow{3}{*}{ Spatial scope } & City & + & - & ++ & + & + & + & ++ \\
\hline & Block & + & - & ++ & + & + & + & ++ \\
\hline & Building & - & ++ & $\cdot$ & $\cdot$ & - & $\cdot$ & ++ \\
\hline \multirow{5}{*}{$\begin{array}{l}\text { Spatial } \\
\text { representation }\end{array}$} & LoD & - & $\cdot$ & - & $\cdot$ & - & - & ++ \\
\hline & 2D Utilities & + & + & ++ & + & + & + & + \\
\hline & 3D Utilities & - & ++ & - & + & - & ++ & ++ \\
\hline & $\begin{array}{l}\text { 2D City } \\
\text { Features } \\
\end{array}$ & ++ & - & ++ & + & - & - & ++ \\
\hline & $\begin{array}{l}\text { 3D City } \\
\text { Features }\end{array}$ & - & - & + & + & - & - & ++ \\
\hline Semantics & & + & ++ & $\bullet$ & + & $\cdot$ & + & ++ \\
\hline \multirow{6}{*}{$\begin{array}{l}\text { Spatial } \\
\text { and logical } \\
\text { relationships }\end{array}$} & $\begin{array}{l}\text { Indoor to } \\
\text { Outdoor } \\
\text { Network }\end{array}$ & - & - & - & • & - & • & + \\
\hline & $\begin{array}{l}\text { Connectivity } \\
\text { Rules }\end{array}$ & - & • & ++ & - & - & - & • \\
\hline & $\begin{array}{l}\text { Network to } \\
\text { City Features }\end{array}$ & - & - & - & • & - & • & ++ \\
\hline & $\begin{array}{l}\text { Network } \\
\text { Itself }\end{array}$ & + & + & ++ & ++ & + & + & ++ \\
\hline & $\begin{array}{l}\text { Network to } \\
\text { Network }\end{array}$ & - & ++ & - & - & - & + & ++ \\
\hline & $\begin{array}{l}\text { Network } \\
\text { for Indoor } \\
\text { Navigation }\end{array}$ & - & - & - & - & - & - & • \\
\hline \multirow[b]{2}{*}{ Visualization } & Realistic & $\bullet$ & ++ & - & + & $\bullet$ & $\cdot$ & ++ \\
\hline & $\begin{array}{l}\text { Iconic/ } \\
\text { Symbols }\end{array}$ & • & - & ++ & - & • & $\bullet$ & • \\
\hline \multicolumn{2}{|c|}{ Sensors/time series data } & - & $\cdot$ & - & + & - & $\cdot$ & - \\
\hline
\end{tabular}

-: Not Supported $\quad$ : Basically Supported + : Supported in Detail ++ : Comprehensively Supported Source: Kutzner et al., 2018, Semantic Modeling of 3D Multi-Utility Networks for Urban Analyses and Simulations: The CityGML Utility Network ADE model.

a reference model for 3D data model development in many countries for this reason, giving it another advantage. Additionally, an advanced conceptual model related to CityGML 3.0 has recently been released. In this conceptual model, a newly added Dynamizer model is included, and the model includes the sensor data connection and Dynamizer-related contents. By considering the changes in issues related to upgrading to CityGML 3.0 and using the extended version of the CityGML Utility Network ADE model proposed in this study, it is expected that a base model that can be linked with various sensor information in the underground space can be prepared. 


\subsection{Extending the reference model using the ADE technique}

To extend the existing CityGML Utility Network ADE model, the previously constructed underground information was mapped with the CityGML Utility Network ADE model. The CityGML Utility Network ADE model consists of six modules centered on the Network Core module (Fig. 1).

The Network Core module is a core element of the CityGML Utility Network ADE model, and it defines the connection and expression of the network and network objects (components). The Feature Material module defines the materials of pipelines and objects. The Functional Characteristics module defines status information related to the use and supply of underground utilities by subject. The Network Components module defines pipelines, lines, and other components (objects). The Geometry of Network Components module defines geometric information related to underground utility objects. Finally, the Network Properties module defines the media (such as water, sewage, and gas) values by underground utilities subject.

As described above, on the basis of the integrated underground facilities system and Integrated Map for Underground Space previously constructed in Korea, the six modules constituting the CityGML Utility Network ADE model were mapped, and the results are as follows. Functional Characteristics, Geometry of Network Components, and Network Properties modules can be used without extension or modification, and we applied their concepts and contents correspondingly. Specifically, the Functional Characteristics module defines the supply function, status, and supplier (or user) for media such as electricity, gas, and liquid (water/ sewage, etc.), and these concepts can be applied without extension. Next, previously constructed underground information defines the geometric forms as points, lines, multi-lines, and areas. The Geometry of Network Components module can define various geometric shapes according

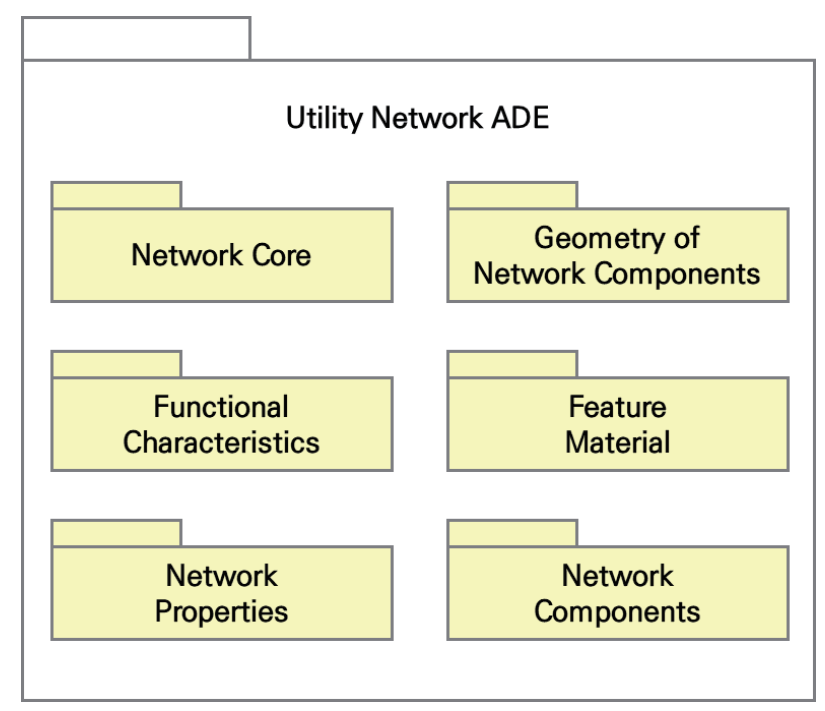

Fig. 1. (Color online) Components of CityGML Utility Network ADE model. 
to the GML notation. Since it supports 2D and 3D related LoD expressions, we applied the existing module as it is. The Network Properties module defines the medium, such as electricity, gas, or liquid, flowing in pipelines and lines. It can cover all media related to the six types of underground utilities as described above. The Network Core, Feature Material, and Network Components modules were mapped for data model extension based on the previously constructed underground information and work regulations specified legally and institutionally. The AbstractNetworkFeatureADE class, which is related to the existing AbstractNetworkFeature class, was added to the Network Core module to reflect attribute values of underground utilities information such as the geographic features code (FTR_CDE), geographic feature number (FTR_IDN), administrative building code (HJD_CDE), and installation date (IST_YMD) (Table 4).

\section{Designing 3D Data Model for Underground Utilities}

As reported in this section, the UML diagram is used for the 3D data model of the pipe-type underground utilities by extending the CityGML Utility Network ADE model based on the underground information previously constructed in Korea. For the UML tool, Enterprise Architect 15.2 provided by Sparx Systems was used.

This study was extended by targeting three modules of the CityGML Utility Network ADE model according to the domestic underground utilities environment based on the results of the mapping performed previously, and the part marked in red indicates the expanded class and code list. As described above, the Functional Characteristics, Network Properties, and Geometry of Network Components modules were designed by applying existing concepts to this study without undergoing a separate extension process as they can be immediately applied to this study.

For the Network Core module, the AbstractNetworkFeatureADE class was added and extended, centering on the AbstractNetworkFeature class, and the attributes commonly included in the underground information previously constructed in Korea were defined (Fig. 2). These attributes were composed of the city/county/borough/statutory town/township/district code (CMC_CDE), geographic feature code (FTR_CDE), geographic feature number (FTR_IDN), administrative area code (HJD_CDE), installation date (IST_YMD), management agency code (MNG_CDE), agency management number (ORG_IDN), and map index number (SHT_NUM). Each attribute was designed by defining domain values in the form of packages.

Next, for the Feature Material module, the existing limited types of materials were added and expanded according to the domestic environment. For this, the MaterialADE class was added to reflect the classification of material-related objects (pipelines, telecommunication posts, etc.), and the types and domain values of underground utility objects related to materials were defined through the class and type attributes (Fig. 3). The UndergroundFacilitiesValue code list is divided into aspirators, communication poles, covers, and pipes to define domain values. 
Table 4

Mapping process.

\begin{tabular}{|c|c|c|c|}
\hline $\begin{array}{l}\text { Existing system } \\
\text { (Integrated map for underground spaces) }\end{array}$ & \multicolumn{3}{|c|}{ CityGML Utility Network ADE } \\
\hline Attributes and domains & & Added and extended & Module name \\
\hline $\begin{array}{l}\text { - CMC_CDE: CMCValue } \\
\text { - FTR_CDE: FTRValue } \\
\text { - FTR_IDN: Integer } \\
\text { - HJD_CDE: HJDValue } \\
\text { - IST_YMD: CharacterString[0..1] } \\
\text { - MNG_CDE: MNGValue } \\
\text { - ORG_IDN: CharacterString[0..1] } \\
\text { - SHT_NUM: CharacterString }\end{array}$ & $\rightarrow$ & $\begin{array}{c}\text { «FeatureType» } \\
\text { AbstractNetworkFeatureADE }\end{array}$ & $\begin{array}{l}\text { Network } \\
\text { core }\end{array}$ \\
\hline $\begin{array}{l}\text { - class: UndergroundFacilitiesValue } \\
\text { - type: MaterialValueADE }\end{array}$ & $\rightarrow$ & $\begin{array}{l}\text { «FeatureType» } \\
\text { MaterialADE }\end{array}$ & \\
\hline - (Package) OGCFacilitiesCodes & $\rightarrow$ & $\begin{array}{l}\text { «CodeList» } \\
\text { MaterialValueADE }\end{array}$ & $\begin{array}{l}\text { Feature } \\
\text { material }\end{array}$ \\
\hline - aspirator, communicationPole, cover, pipe & $\rightarrow$ & $\begin{array}{c}\text { «CodeList» } \\
\text { UndergroundFacilitiesValue }\end{array}$ & \\
\hline $\begin{array}{l}\text { - class: UndergroundFacilitiesPipe } \\
\text { - pipeDepth: Double }\end{array}$ & $\rightarrow$ & $\begin{array}{c}\text { «FeatureType» } \\
\text { AbstractPipeADE }\end{array}$ & \\
\hline - class: ComplexFunctionalComponentValueADE & $\rightarrow$ & $\begin{array}{c}\text { «FeatureType» } \\
\text { ComplexFunctionalComponentADE }\end{array}$ & \\
\hline - class: MeasurementComponent ValueADE & $\rightarrow$ & $\begin{array}{c}\text { «FeatureType» } \\
\text { MeasurementComponentADE }\end{array}$ & \\
\hline - class: ConnectionComponentValueADE & $\rightarrow$ & $\begin{array}{c}\text { «FeatureType» } \\
\text { ConnectionComponentADE }\end{array}$ & \\
\hline - class: ControllerComponentValueADE & $\rightarrow$ & $\begin{array}{c}\text { «FeatureType» } \\
\text { ControllerComponentADE }\end{array}$ & \\
\hline - class: StorageComponentValueADE & $\rightarrow$ & $\begin{array}{c}\text { «FeatureType» } \\
\text { StorageComponentADE }\end{array}$ & \\
\hline - class: TerminalComponentValue ADE & $\rightarrow$ & $\begin{array}{c}\text { «FeatureType» } \\
\text { TerminalComponentADE }\end{array}$ & \\
\hline - class: VentComponentValue & $\rightarrow$ & $\begin{array}{l}\text { «FeatureType» } \\
\text { VentComponent } \\
\end{array}$ & \\
\hline $\begin{array}{l}\text { - heatingPipe, lpgPipe, naturalGasPipe, } \\
\text { powerCablePipe, serviceWaterPipe, sewagePipe, } \\
\text { waterSupplyPipe }\end{array}$ & $\rightarrow$ & $\begin{array}{l}\text { «CodeList» } \\
\text { UndergroundFacilitiesPipe }\end{array}$ & components \\
\hline $\begin{array}{l}\text { - catchmentArea, disposalArea, drainageArea, } \\
\text { intakeStation, purificationPlant, sewerOutlet }\end{array}$ & & $\begin{array}{l}\text { «CodeList» } \\
\text { ComplexFunctionalComponentValueADE }\end{array}$ & \\
\hline $\begin{array}{l}\text { - flowmeter, governor, hydrantMeter, } \\
\text { waterPressureGauge }\end{array}$ & $\rightarrow$ & $\begin{array}{c}\text { «CodeList» } \\
\text { MeasurementComponentValueADE } \\
\end{array}$ & \\
\hline $\begin{array}{l}\text { - disposalSector, drainageSector, } \\
\text { standpipe, powerDistributionCableTunnel, } \\
\text { powerTransmissionCableTunnel, } \\
\text { sewageConnectionPipe, sideDitch }\end{array}$ & $\rightarrow$ & $\begin{array}{c}\text { «CodeList» } \\
\text { ConnectionComponentValueADE }\end{array}$ & \\
\hline $\begin{array}{l}\text { - heatingPanel, leakLocationRecoveryHistory, } \\
\text { testBox }\end{array}$ & $\rightarrow$ & $\begin{array}{c}\text { «CodeList» } \\
\text { ControllerComponentADE }\end{array}$ & \\
\hline $\begin{array}{l}\text { - reservoir, retardingBasin, distributionReservoir, } \\
\text { stormWaterSoilChamber, waterspout }\end{array}$ & $\rightarrow$ & $\begin{array}{c}\text { «CodeList» } \\
\text { StorageComponentValueADE }\end{array}$ & \\
\hline - fireProtectionFacilities, handhole, pole & $\rightarrow$ & $\begin{array}{c}\text { «CodeList» } \\
\text { TerminalComponentValueADE }\end{array}$ & \\
\hline
\end{tabular}




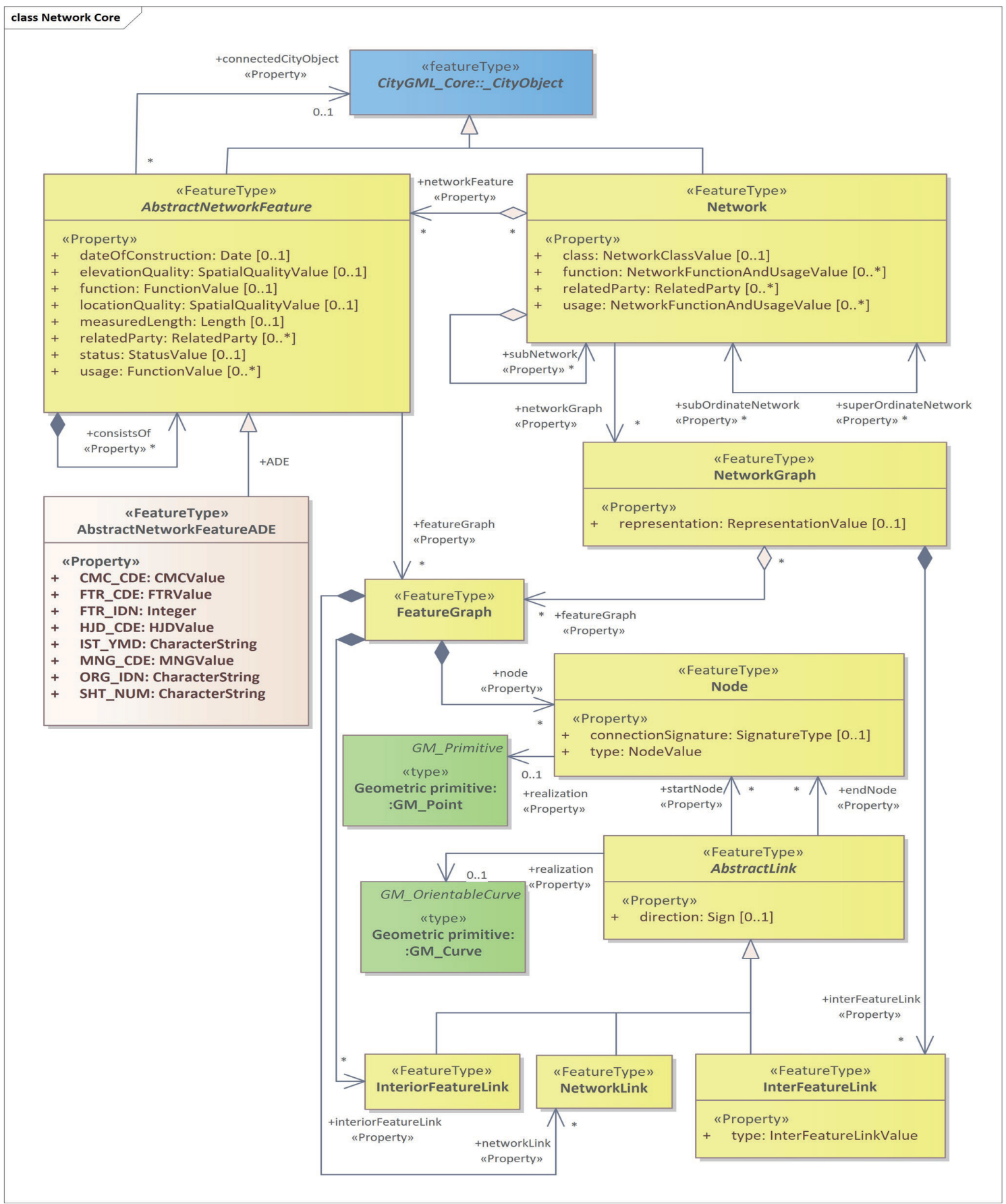

Fig. 2. (Color online) Extended components of the Network Core module. 


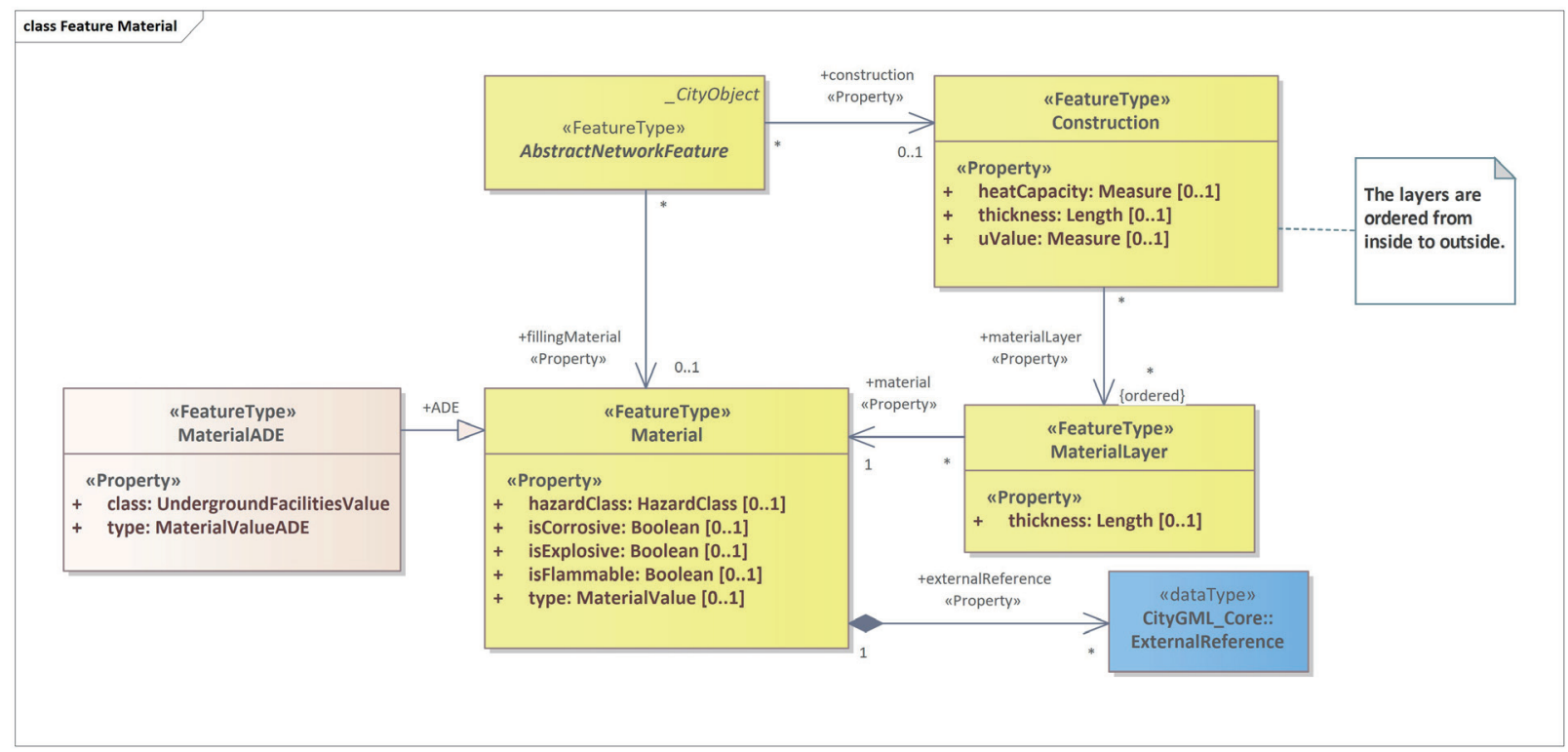

Fig. 3. (Color online) Extended components of Feature Material module.

Finally, for the Network Components module, the existing limited underground utility objects are expanded to suit the domestic environment so that various objects can be expressed by underground utilities subjects. For this, classes and code lists for classifying pipelines by underground utilities subjects and for expressing the depth were defined, and classes and code lists for each component were added and expanded to support the expressions and functions of various objects related to domestic underground utilities.

The following are detailed descriptions of the extension. First, it was defined to include the attributes related to the type and depth of the underground utilities (Fig. 4) by adding the AbstractPipeADE class. Then, for the previously established underground information, separate depth information was constructed and used to express the depth value of the underground utility pipeline objects. However, as this method does not include various underground utility objects and does not guarantee an accurate depth for each object, we defined the depth information to be expressed as a single attribute value (Fig. 5). 


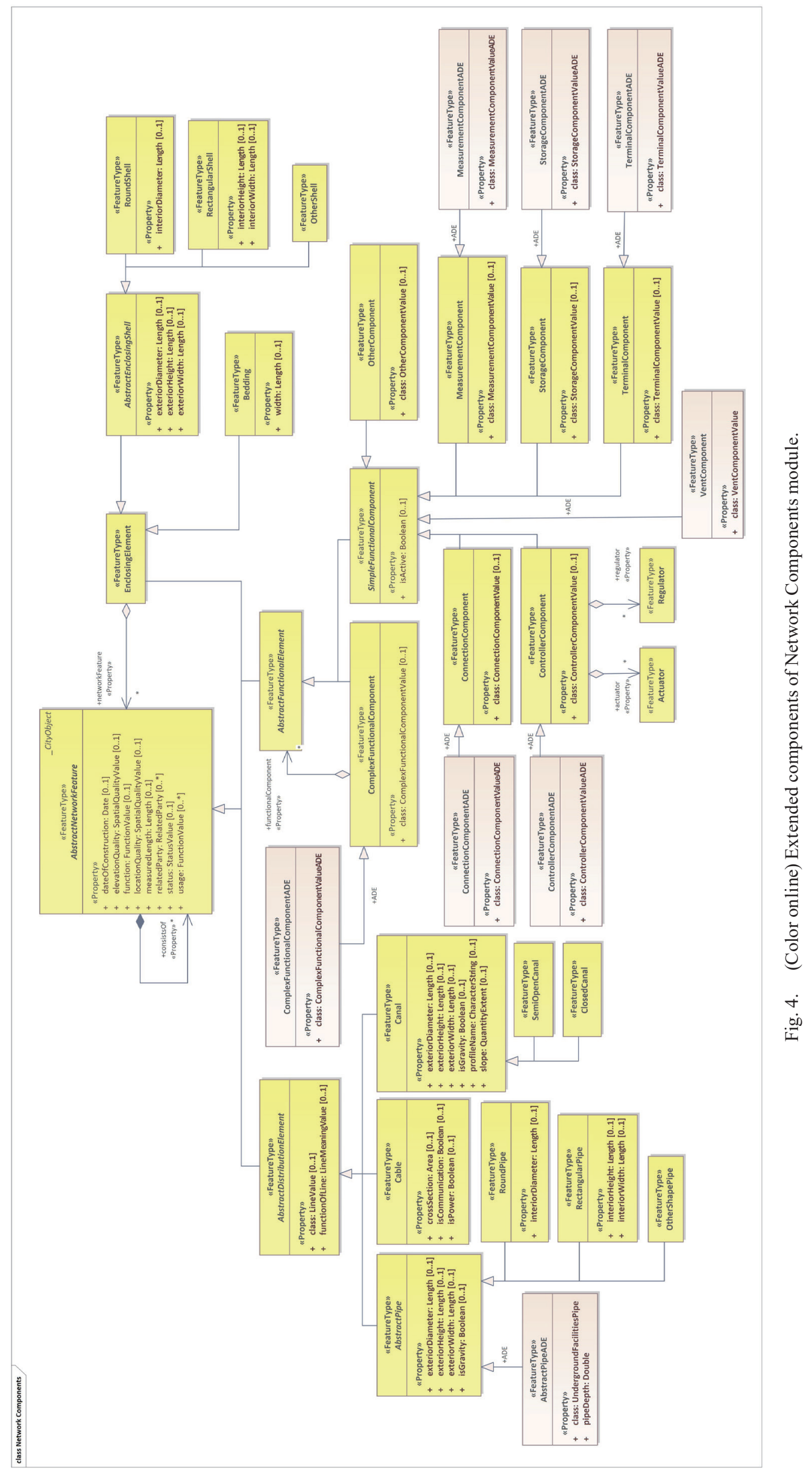




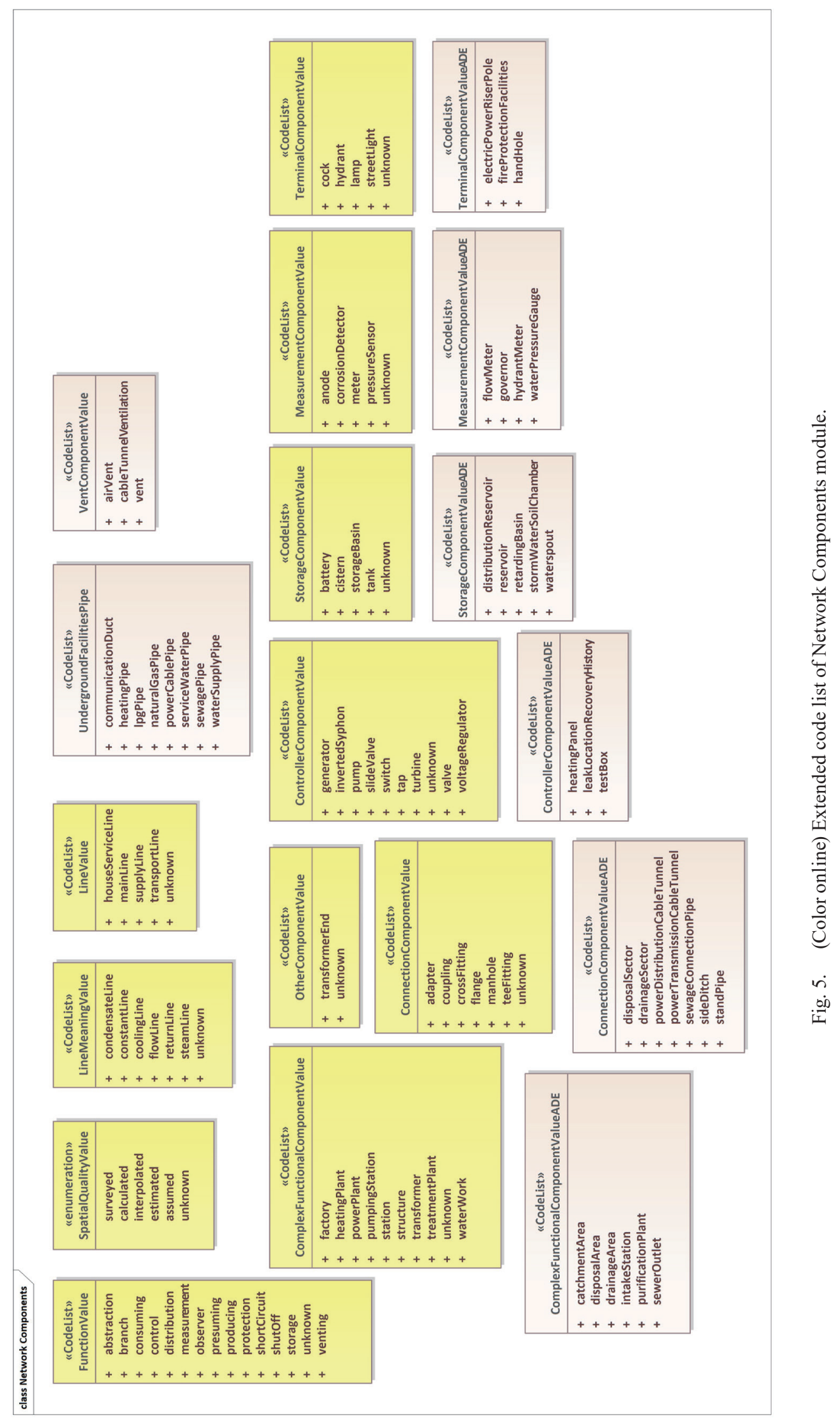




\section{Conclusions}

The aims of this study were to determine how to establish a 3D data model in the light of the international standards for spatial information for six pipe-type underground utilities specified in the Regulations on the Production of the Integrated Map for Underground Spaces, and to design a logical model of the 3D data model through the expansion of the CityGML Utility Network ADE model.

For this purpose, the status of existing underground information-related systems and preceding domestic and foreign studies were reviewed to present the current status and implications for underground utilities information and to clarify the difference of this study and its academic significance. Next, we explored the necessity of a 3D data model for pipe-type underground utilities and methods to establish such a model, and established a 3D data model for underground utilities based on the topics discussed in this study. To establish a 3D data model of pipe-type underground utilities, a reference model for expressing the data model as spatial information was selected by comparing and reviewing international standards that became the basis of the data model. Then, the mapping process was performed on the basis of attributes and domains used in the existing information-related system. Finally, a logical model that extends the CityGML Utility Network ADE model, used as a reference model, was designed using the UML diagram based on the contents of the established 3D data model of the pipe-type underground utilities.

As described, we aimed to improve the accuracy and quality of existing underground information by designing a 3D data model of pipe-type underground utilities. It is expected to be possible to expand its application to related areas and utilize it for various analyses of a higherdimensional space by applying international standards correspondingly. As previously mentioned, existing studies only went as far as expressing underground utilities as a $2 \mathrm{D}$ network or visualizing them in three dimensions, focusing on pipelines. This study is characterized by and has academic significance for presenting an integrated 3D data model based on international standards, which enables interconnection and operation between above-ground and underground spaces. In addition, the data model was established for future underground data management and monitoring by linking it with various sensor data.

The outcomes of this study are expected to improve the utilization of underground information by providing underground information with enhanced consistency with the real world through the 3D data model of the pipe-type underground utilities. It is also expected to be used as a fundamental technology to expand the base for supporting interoperability through the connection and utilization of underground information in various related fields, such as the underground safety information system, which is one of Korea's national information systems.

\section{Acknowledgments}

This work was supported by a Korea Agency for Infrastructure Technology Advancement (KAIA) grant funded by the Ministry of Land, Infrastructure and Transport (Grant 21DCRU-B158151-02). 


\section{References}

1 Y. G. Jang, D. H. Park, J. Y. Woo, and W. K. Lee: Proc. Korean Society of Civil Engineers (Korea, 2015) 119120.

2 Board of Audit and Inspection: 2017 Audit Report (BAI, Seoul, Korea, 2017).

3 Korea Institute of Construction Technology: 2019 The Report to Technology Development Planning about Automatic Updating and Utilization Support for Exploration Sites in the Integrated Map of Underground Spaces (KICT, Goyang, Korea, 2019).

4 T. Becker, C. Nagel, and T. H. Kolbe: Adv. 3D Geo-Inf. Sci. 1 (2011) 37. https://doi.org/10.1007/978-3-64212670-3 1

5 I. Hijazi, M. Ehlers, S. Zlatanova, T. Adolphi, and L. Berlo: Adv. 3D Geo-Inf. Sci. 37 (2011) 6. https://doi. org/10.1007/978-3-642-12670-3 6

6 T. Becker, C. Nagel, and T. H. Kolbe: Progress New Trends 3D Geoinf. Sci. 51 (2012) 3. https://doi. org/10.1007/978-3-642-29793-9 3

7 T. Kutzner and T. H. Kolbe: Proc. Dreiländertagung der SGPF, DGPF und OVG (DGPF, 2016) 382-394.

8 T. Kutzner and T. H. Kolbe: Proc. Underground Infrastructure Mapping and Modeling Workshop (OGC, 2017) $1-34$.

9 I. Boates, G. Agugiaro, and A. Nichersu: Proc. ISPRS TC IV Mid-term Symp. (Netherlands, 2018) 13-20.

10 X. D. Duijn, G. Agugiaro, and S. Zlatanova: Proc. 3rd Int. Conf. Smart Data and Smart Cities (Netherlands, 2018) 43-50.

11 T. Kutzner, T. H. Kolbe, and I. Hijazi: Int. J. 3-D Inf. Modeling 7 (2018) 2. https://doi.org/10.4018/ IJ3DIM.2018040101

12 S. Ortega, J. Wendel, J. M. Santana, S. M. Murshed, I. Boates, A. Trujillo, A. Nichersu, and J. P. Suárez: Int. J. Geo-Inf. 8 (2019) 3. https://doi.org/10.3390/ijgi8030152

13 D. W. Jeong, S. C. Yu, K. J. Min, J. Y. Lee, and J. W. Ahn: J. Korean Soc. Surv. Geodesy Photogramm. Cartography 38 (2020) 6. https://doi.org/10.7848/ksgpc.2020.38.6.533

14 D. W. Jeong, S. C. Yu, K. J. Min, J. Y. Lee, and J. W. Ahn: J. Korean Soc. Geospatial Inf. Sci. 29 (2021) 1. https://doi.org/10.7319/kogsis.2021.29.1.013

15 Open Geospatial Consortium: OGC Engineering Report-OGC 17-048 (OGC, Wayland, Massachusetts, USA, 2017).

16 Open Geospatial Consortium: OGC Engineering Report-OGC 18-073r2 (OGC, Wayland, Massachusetts, USA, 2019).

17 J. Lieberman: Proc. OGC MUDDI ETL-Plugfest Workshop (USA, 2018) 1-23.

18 Open Geospatial Consortium: OGC Engineering Report-OGC 12-019 (OGC, Wayland, Massachusetts, USA, 2012).

\section{About the Authors}

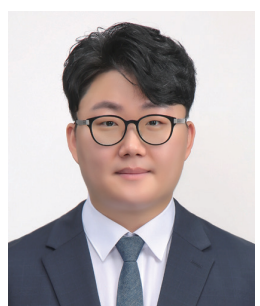

Da Woon Jeong received his B.S., M.S., and Ph.D. degrees from Anyang University, Korea, in 2014, 2016, and 2021, respectively. Since 2021, he has been a senior research engineer at the Smart Urban Space Institute in Anyang University. His research interests are in smart cities, spatial information, and standards for spatial information.

(daun5342@gmail.com)

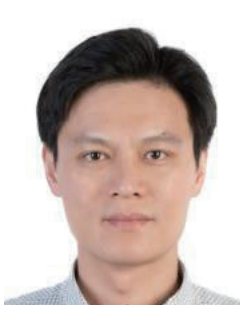

Seon Cheol Yu received his B.S., M.S., and Ph.D. degrees from Anyang University, Korea, in 2003, 2005, and 2011, respectively. From 2011 to 2014, he was an associate research fellow at the Korea Research Institute for Human Settlement, Korea. Since 2021, he has been a professor at Anyang University. His research interests are in urban planning, big data, smart cities, and urban regeneration. (scyu@anyang.ac.kr) 


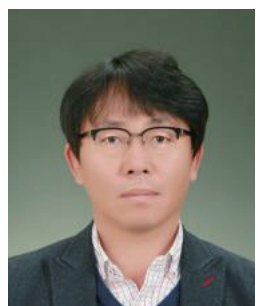

Jong Wook Ahn received his B.S., M.S., and Ph.D. degrees from Anyang University, Korea, in 2000, 2002, and 2007, respectively. From 2007 to 2011, he was an associate research fellow at the Korea Research Institute for Human Settlement, Korea. Since 2011, he has been a professor at Anyang University. His research interests are in urban planning, smart cities, big data, and spatial information.

(ajw0603@anyang.ac.kr) 